\title{
Faktor pendorong purchase intention produk sustainable fashion pada UMKM
}

\author{
Rike Penta Sitio* \\ Sekolah Tinggi Manajemen PPM, Jalan Menteng Raya No. 9 Kebon Sirih, Menteng, Kota \\ Jakarta Pusat, DKI Jakarta, 10340, Indonesia \\ rik@ppm-manajemen.ac.id \\ Rosita Fitriyani \\ Sekolah Tinggi Manajemen PPM, Jalan Menteng Raya No. 9 Kebon Sirih, Menteng, Kota \\ Jakarta Pusat, DKI Jakarta, 10340, Indonesia \\ ros@ppm-manajemen.ac.id
}

\section{Anggun Pesona Intan}

Sekolah Tinggi Manajemen PPM, Jalan Menteng Raya No. 9 Kebon Sirih, Menteng, Kota

Jakarta Pusat, DKI Jakarta, 10340, Indonesia

api@ppm-manajemen.ac.id

*Penulis Korespondensi

Submitted: Oct 7, 2021; Reviewed: Oct 16, 2021; Accepted: Nov 6, 2021

\begin{abstract}
The creative fashion industry is one of the sources of economic strength in great demand by businessman and consumers, such as MSMEs. The purpose of this study was to examine the effect of consumer knowledge on purchase intention in MSMEs sustainable fashion products with trust as a mediator variable. The research method will use quantitative research. The samples obtained were 257 consumers of Indonesian MSMEs fast fashion products and used the Qualtrics electronic questionnaire. This research data is from perception data for sustainable fashion knowledge variables, trust, and purchase intention in MSMEs sustainable fashion products. The data were processed using SPSS to test the validity, reliability, regression analysis, and mediation test using JASP. The results obtained are that consumers who know sustainable fashion will make these consumers more confident in sustainable fashion MSMEs products and ultimately increase consumer purchase intention in MSMEs sustainable fashion products. So, it is very important for MSMEs engaged in the sustainable fashion business to educate consumers about the meaning of sustainable fashion and the practice of MSMEs in a sustainable fashion.
\end{abstract}

Keywords: MSMEs; perception; purchase intention; sustainable fashion; trust

Abstrak: Industri kreatif fashion merupakan salah satu sumber kekuatan perekonomian yang banyak diminati para pelaku usaha dan konsumen, seperti UMKM. Tujuan penelitian ini untuk menguji pengaruh knowledge konsumen terhadap purchase intention produk UMKM sustainable fashion dengan kepercayaan sebagai variabel mediator. Metode penelitian akan menggunakan penelitian kuantitatif. Sampel yang diperoleh sebanyak 257 orang konsumen produk fast fashion UMKM Indonesia dan menggunakan kuesioner elektronik Qualtrics. Data penelitian ini berupa data persepsi untuk variabel knowledge fashion yang berkelanjutan, kepercayaan, dan purchase intention terhadap produk 
sustainable fashion UMKM. Data diolah menggunakan SPSS untuk menguji validitas serta reliabilitas dan analisis regresi serta uji mediasi menggunakan JASP. Hasil penelitian yang didapatkan adalah bahwa konsumen yang memiliki knowledge akan fashion yang berkelanjutan akan membuat konsumen tersebut lebih percaya dengan produk UMKM sustainable fashion dan akhirnya meningkatkan purchase intention konsumen tersebut akan produk UMKM sustainable fashion. Sehingga penting sekali untuk UMKM yang bergerak di usaha sustainable fashion untuk mengedukasi konsumen mengenai makna sustainable fashion dan praktik UMKM sustainable fashion.

Kata kunci: kepercayaan; persepsi; purchase intention; sustainable fashion; UMKM

\section{PENDAHULUAN}

Sektor ekonomi kreatif merupakan sumber dan kekuatan ekonomi baru, terutama untuk Indonesia, di mana harga komoditas dan bahan mentah terus menurun di pasar global. Badan Ekonomi Kreatif menyebutkan bahwa PDB Ekonomi di Indonesia telah didominasi oleh 3 subsektor dari 16 sektor kreatif di Indonesia. Subsektor pertama didominasi oleh sektor kuliner sebesar 41,96\%, kemudian industri di sektor fashion menempati urutan kedua dalam kontribusinya, sebesar 18,5\%, dan bidang kriya sebesar $15,70 \%$. Selain dalam kontribusi PDB, industri kreatif fashion merupakan salah satu ekspor ekraf tertinggi di Indonesia yaitu sebesar 56\% (Direktorat Riset dan Pengembangan Ekonomi Kreatif Deputi Riset Edukasi dan Pengembangan Badan Ekonomi Kreatif, 2017). Hal ini menunjukan bahwa fashion memiliki kontribusi yang cukup besar bagi perkembangan ekonomi dan industri kreatif di Indonesia, dengan tingkat konsumerisme yang tinggi.

Di lain pihak, industri kreatif fashion dikatakan sebagai penyumbang kerusakan lingkungan yang utama dikarenakan jejak polusi yang ditinggalkannya pada setiap tahapan siklus produk fashion tersebut (Claudio, 2007; Garcia-Torres et al., 2017). Binet et al. (2018) mengemukakan bahwa perkembangan industri fashion akan terus bertambah pesat hingga tahun 2030 di mana industri ini diperkirakan tumbuh sebanyak 50\% dan mengakibatkan jejak karbon yang ditinggalkan menjadi 2.791 ton dan limbah yang dihasilkan akan mencapai 148 ton. Fakta ini membuat berbagai pelaku usaha pada industri fashion di luar negeri mengupayakan pengurangan tingkat polusi air hingga 50\% dan memiliki kemungkinan menerapkan skema pengolahan bahan kimia dan limbah tekstil.

Perbaikan yang dilakukan oleh industri fashion di luar negeri berbeda dengan kondisi di Indonesia, di mana mayoritas UMKM sebagai pelaku usaha seringkali ikut menjadi kontributor kerusakan lingkungan (Bank Indonesia, 2012). Dampak negatif yang disebabkan oleh UMKM dimulai dari pemilihan bahan baku, proses produksi, dan limbah yang dihasilkan saat produksi maupun pasca produksi. Berdasarkan penelitian yang dilakukan Bank Indonesia (2012), disebutkan bahwa kendala utama yang dihadapi untuk menjadi usaha yang ramah lingkungan adalah lokasi usaha dan persoalan limbah produksi. Lebih lanjut penelitian ini juga mengemukakan bahwa UMKM industri, dalam hal ini termasuk industri fashion, belum melakukan kegiatan usaha sesuai dengan kriteria industri hijau secara komprehensif. Masalah pengetahuan akan bisnis yang berkelanjutan, pemodalan, dan SDM membuat UMKM sulit untuk dapat fokus pada aspek keberlanjutan, yang salah satunya adalah kelestarian lingkungan hijau. Namun, masalah krusial yang membuat UMKM fashion enggan untuk memperhatikan kelestarian lingkungan dalam bisnisnya adalah rendahnya animo konsumen Indonesia terhadap aspek kelestarian lingkungan. Konsumen di Indonesia tidak terlalu mempertimbangkan cara perusahaan melakukan bisnisnya dengan menjadi perusahaan yang ramah lingkungan (Susilo, 2014). Hal ini menunjukkan belum adanya perilaku konsumsi yang bertanggung jawab. Reisch et al. (2013) menunjukkan sustainable consumption sebagai usaha untuk menyediakan barang dan jasa yang tersedia untuk semua manusia di dunia, sambil meminimalkan penggunaan sumber daya alam, energi, kegiatan efisiensi lahan dan gaya hidup yang berkecukupan. Meulenberg (2003) lebih lanjut mengatakan bahwa perilaku konsumsi yang bertanggung jawab dikenal dengan sustainable consumption, di mana perilaku ini didasarkan pada proses pengambilan keputusan dengan mempertimbangkan tanggung jawab sosial konsumen di samping kebutuhan dan keinginan individu. Quoquab et al. (2019) mengatakan bahwa tindakan atau perilaku yang berusaha mengendalikan keinginan diri dan menghindari pembelian yang berlebihan serta menggunakan barang dan jasa untuk memenuhi kebutuhan dasar disebut sustainable consumption. 
Pengetahuan (knowledge) terhadap keberlangsungan lingkungan tampak dari perubahan perilaku yang lebih ramah lingkungan seperti bike to work, perilaku daur ulang, dan perilaku konsumsi yang bertanggung jawab (Meulenberg, 2003). Rosadi (2021)menyebutkan bahwa baru 28\% konsumen Indonesia betul-betul memahami produk berkelanjutan, artinya mayoritas konsumen Indonesia tidak memiliki pemahaman akan produk yang berkelanjutan, di mana salah satunya adalah fashion yang berkelanjutan (sustainable fashion). Minimnya pengetahuan fashion yang berkelanjutan ini akan mendorong sustainable fashion products consumption ke arah yang negatif (Han et al., 2017). Pengetahuan ataupun informasi mengenai perubahan perilaku konsumen yang menjadi lebih bertanggung jawab, tentunya akan sangat penting untuk para pelaku usaha di berbagai industri. Persepsi konsumen mengenai pengetahuan (knowledge) fashion yang berkelanjutan menurut Shen et al. (2013) merupakan penggabungan makna pengetahuan dari dimensi hijau dan dimensi etis dari fashion. Sustainable fashion atau fashion yang berkelanjutan merupakan bagian dari slow fashion (fashion lambat) dan istilahnya sering digunakan secara bergantian dengan fashion yang ramah lingkungan, fashion hijau ataupun fashion yang beretika (Carey \& Cervellon, 2014). Fashion yang hijau artinya adalah penggunaan bahan daur ulang yang dapat terurai secara hayati, sedangkan fashion yang etis lebih berfokus pada prinsip perdagangan yang adil dan sistem produksi yang bebas dari kondisi dari tenaga kerja yang tidak sesuai dengan ketentuan hukum, seperti waktu kerja yang panjang, tenaga kerja di bawah umur, dan upah di bawah standar. Perubahan perilaku pada konsumerisme memiliki dampak secara langsung dan salah satu tantangan terbesar terhadap lingkungan sekitar (Kostadinova, 2016). Selain itu, persepsi konsumen terhadap pemasok menjadi dasar di mana konsumen menentukan apakah akan memercayai klaim produsen bahwa produk dan praktik mereka berkelanjutan (Bonn et al., 2016).

Rosadi (2021) memaparkan bahwa dari $28 \%$ konsumen yang yang memiliki pengetahuan mengenai produk yang berkelanjutan akan bersedia membayar dengan harga yang lebih tinggi jika konsumen meyakini akan keberlanjutan produk tersebut, sehingga dapat diartikan jika konsumen memiliki kepercayaan bahwa suatu produk berkelanjutan, maka konsumen ingin berkontribusi melalui pembelian produk. Hal ini sejalan dengan hasil penelitian Wang et al. (2019) yang menyebutkan bahwa purchase intention tidak hanya ditentukan langsung oleh adanya pengetahuan konsumen, namun ada variabel perantara yang diperlukan untuk mendorong pengetahuan konsumen sehingga dapat berubah menjadi suatu purchase intention. Variabel yang dimaksud oleh Wang et al (2019) adalah kepercayaan. Kepercayaan merupakan prediktor signifikan untuk hasil pemasaran yang positif, seperti loyalitas, retensi pelanggan, dan niat membeli. Oleh karena itu, hal tersebut sangat penting bagi perusahaan untuk membangun hubungan yang dapat dipercaya dengan pelanggannya (Neumann et al., 2020). Hal ini semakin menguatkan pentingnya pengetahuan konsumen akan arti produk berkelanjutan secara utuh supaya timbul kepercayaan yang akan mendukung adanya purchase intention. Studi lain yang dilakukan oleh Wang et al (2019) menunjukkan bahwa tingkat pengetahuan konsumen dan sikap konsumen terhadap produk ramah lingkungan dan berkelanjutan berhubungan langsung dengan purchase intention (niat beli) konsumen, di mana kepercayaan dapat menjelaskan transformasi pengetahuan yang dimiliki konsumen menjadi suatu niat beli.

Berdasarkan latar belakang di atas, maka penelitian mengenai pengetahuan konsumen UMKM sustainable fashion dan kepercayaan konsumen terhadap produk sustainable fashion perlu dilakukan agar dapat memprediksi purchase intention konsumen akan produk UMKM sustainable fashion. Adapun tujuan penelitian ini untuk menguji pengaruh knowledge konsumen mengenai sustainable fashion terhadap purchase intention produk sustainable fashion yang dimediasi oleh kepercayaan produk UMKM sustainable fashion.

Studi terkait sustainability ataupun keberlanjutan dalam industri fashion memerlukan pendekatan yang holistik. Studi ini bukan hanya berbicara mengenai praktik keberlanjutan dari suatu usaha, namun perlu diawali dengan memahami persepsi konsumen terhadap fashion yang berkelanjutan (Suk, 2015). Pada dasarnya setiap konsumen melakukan pembelian pasti berdasarkan rasa percaya, di mana hal ini menunjukkan bahwa kepercayaan pada konsumen dalam suatu industri dapat meredam persepsi risiko pada pengetahuan (knowledge) konsumen itu sendiri terhadap produk atau barang yang akan dibeli (Martinayanti \& Setiawan, 2016). Han et al. (2017) juga dalam penelitiannya turut menyatakan bahwa pengetahuan disorot di dalam ilmu perilaku konsumen sebagai dasar yang kuat untuk membentuk kepercayaan. Pengetahuan didefinisikan sebagai informasi yang disimpan dalam ingatan konsumen serta memengaruhi evaluasi konsumen dalam menerjemahkan informasi, preferensi produk, dan perilaku pembelian konsumen akan fashion yang berkelanjutan (Shen et al., 2013; Wang et al., 2019). 
Wang et al (2019) menyebutkan bahwa konsumen menunjukkan sikap yang lebih positif terhadap fashion yang berkelanjutan jika memiliki pengetahuan sehingga menjadi lebih yakin mengenai keandalan fashion dalam melindungi lingkungan. Keyakinan sendiri dimaknai sebagai suatu level kepercayaan (Chen \& Chang, 2012). Hal ini menunjukkan bahwa konsumen perlu memiliki pengetahuan mengenai produk yang berkelanjutan untuk mendorong level kepercayaan konsumen terhadap kehandalan produk tersebut sebagai produk yang ramah lingkungan dan etis, sebagai bagian dari makna fashion yang berkelanjutan (Liu et al., 2021). Berdasarkan hasil penelitian Wang et al. (2019), pengetahuan akan produk hijau memiliki pengaruh terhadap kepercayaan dan kepercayaan sendiri menjadi mediator hubungan antara pengetahuan dengan purchase intention. Hasil penelitian tersebut sejalan dengan penelitian Suk (2015) yang menyatakan bahwa pengetahuan konsumen terhadap fashion yang berkelanjutan berpengaruh signifikan terhadap kepercayaan konsumen, seperti yang menjadi hasil penelitian dari Suk (2015). Berdasarkan hal ini, maka hipotesis yang akan kami kembangkan adalah:

$\mathrm{H}_{1}$ : Pengetahuan fashion yang berkelanjutan yang dimiliki konsumen memengaruhi kepercayaan (trust) konsumen.

$\mathrm{H}_{4}$ : Persepsi konsumen mengenai pengetahuan (knowledge) fashion yang berkelanjutan memiliki pengaruh tidak langsung terhadap purchase intention melalui kepercayaan sebagai variabel mediator.

Pada penjelasan di bagian sebelumnya, disebutkan bahwa persepsi konsumen mengenai pengetahuan (knowledge) fashion yang berkelanjutan memengaruhi kepercayaan konsumen terhadap suatu produk (Suk, 2015), sementara Neumann et al. (2020) menyatakan kepercayaan (trust) memengaruhi secara langsung purchase intention. Neuman et al. (2020) lebih lanjut menyatakan bahwa kepercayaan merupakan predictor yang positif dari loyalitas, retensi pelanggan, dan purchase intention. Kepercayaan dinilai merupakan pendorong yang kuat bagi seseorang menentukan niatnya untuk membeli. Sehingga hipotesis yang akan dijawab melalui penelitian ini adalah:

$\mathrm{H}_{3}$ : Terdapat pengaruh signifikan antara kepercayaan terhadap purchase intention produk UMKM sustainable fashion.

Penelitian mengenai dampak pengetahuan terhadap purchase intention yang dilakukan Mei et al. (2012) menunjukkan bahwa pengetahuan akan kelestarian lingkuan (sustainability) memengaruhi niat beli konsumen. Lebih lanjut Mei et al. (2019) menyatakan pengetahuan seseorang tentang suatu masalah berdampak signifikan pada pengambilan keputusan konsumen dan konsumen tidak suka serta cenderung menghindari situasi di mana dirinya tidak memiliki cukup pengetahuan untuk memandu perilaku mereka, sehingga konsumen sustainable fashion cenderung membekali diri mereka dengan pemahaman mengenai keberlanjutan sebelum berniat melakukan pembelian. Berdasarkan hal tersebut, maka hipotesis yang coba diteliti adalah:

$\mathrm{H}_{2}$ : Terdapat pengaruh signifikan antara pengetahuan (knowledge) fashion yang berkelanjutan terhadap purchase intention UMKM sustainable fashion.

Berdasarkan penelusuran pada kajian pustaka dan hasil penelitian sebelumnya, maka model penelitian ini dapat digambarkan seperti pada Gambar 1 .

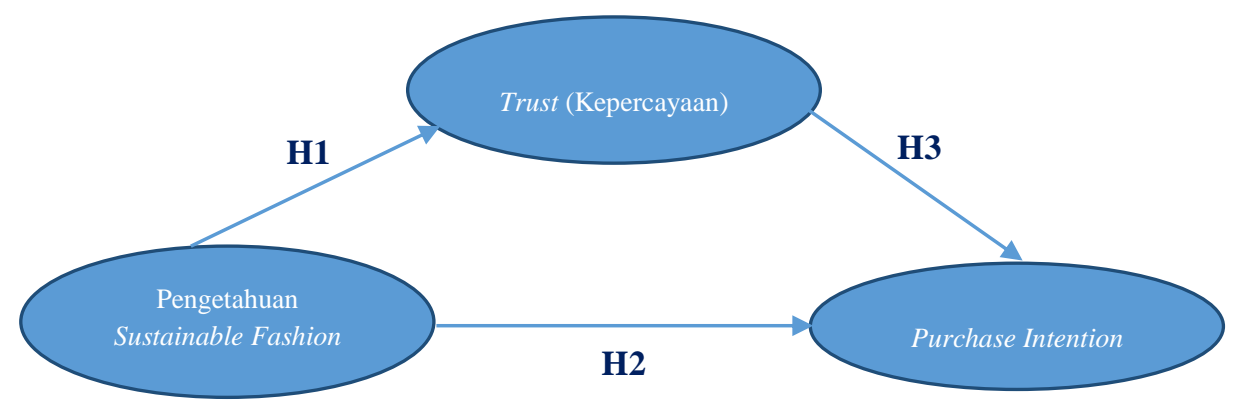

Gambar 1. Model penelitian

Sumber: Hasil analisis peneliti (2021) 


\section{METODE}

Metode penelitian menggunakan penelitian kuantitatif. Penelitian dilakukan melalui pengumpulan data primer. Data primer diperoleh melalui survei dengan kuesioner dengan single cross-sectional design. Pengambilan data primer melalui survei dilakukan dengan menggunakan electronic questionnaire melalui Qualtrics. Pengambilan data menggunakan kuesioner bersifat terstruktur yang artinya responden diberikan beberapa alternatif jawaban untuk dipilih. Terdapat 2 skala yang akan digunakan dalam kuesioner ini, yaitu skala nominal dan skala interval. Untuk skala interval, menggunakan skala Likert dengan 5 kategori respon yang menunjukkan tingkat persetujuan atas pertanyaan dalam kuesioner.

Populasi target adalah konsumen produk fashion UMKM sustainable fashion berdomisili di Jabodetabek dan memiliki penghasilan di atas UMR. Menurut Putra (2020), khusus untuk wilayah DKI Jakarta terdapat 4.836.977 orang yang bekerja dan memiliki UMR di atas rata-rata. Teknik sampling pada penelitian kuantitatif ini menggunakan teknik non-probability sampling dengan metode purposive sampling. Target sampel sebanyak 384 orang konsumen produk fast fashion UMKM Indonesia dan menggunakan kuesioner elektronik Qualtrics. Penentuan jumlah sampel didasarkan aturan atau formula dari Krejcie \& Morgan (1970), di mana jika jumlah populasi di atas 1.000 .000 maka jumlah sampel yang diperlukan sebanyak 384 sampel. Namun dari hasil penyebaran kuesioner yang dilakukan, penulis mendapatkan 257 orang responden yang dapat menjawab sampai dengan akhir kuesioner. Data penelitian ini berupa data persepsi konsumen mengenai knowledge fashion yang berkelanjutan, kepercayaan, dan purchase intention terhadap produk fashion UMKM sustainable fashion. Validitas dilakukan menggunakan analisis faktor dan reliabilitas dilakukan dengan menggunakan nilai Cronbach Alpha. Uji asumsi klasik dilakukan sebelum dilanjutkan dengan analisis regresi. Semua proses dilakukan dengan menggunakan software SPSS. Sofware Jesffrey's Amazing Statistics Program (JASP) digunakan untuk menguji regresi dan untuk menguji pengaruh langsung dan tidak langsung dari model penelitian. Kelebihan dari penggunaan software ini adalah dapat menguji pengaruh langsung dan tidak langsung model penelitian dengan satu kali operasi.

\section{HASIL DAN PEMBAHASAN}

\subsection{Gambaran responden}

Tabel 1 menunjukkan bahwa responden penelitian ini terdiri dari 257 orang responden, di mana 63\% adalah wanita dan $37 \%$ adalah pria. Berdasarkan hasil sebaran kuesioner, rata-rata frekuensi pembelian pakaian yang dilakukan oleh konsumen mayoritas sebanyak 2-3 bulan sekali, baik wanita maupun pria, sedangkan kategori usia yang berbelanja pakaian 2-3 bulan sekali mayoritas berada di rentang usia 39,156 tahun sebanyak 52,2 \%, dan usia 30,1-39 tahun sebanyak 41\%. Pembelian pakaian yang dilakukan oleh responden tidak melihat apakah responden membeli pakaian fast fashion ataukah sustainable fashion.

Tabel 1. Hasil crosstab rentang usia dan frekuensi pembelian pakaian

\begin{tabular}{lrrrrr}
\hline & \multicolumn{5}{c}{ Usia } \\
\cline { 2 - 6 } & $\leq 18$ & $18,1-30$ & $30,1-39$ & $39,1-56$ & $>56$ \\
\hline \multicolumn{1}{c}{ Frekuensi } & & & & & \\
2-3 kali dalam 1 minggu & $0,0 \%$ & $1,6 \%$ & $3,4 \%$ & $0,0 \%$ & $0,0 \%$ \\
1 kali dalam seminggu & $0,0 \%$ & $0,8 \%$ & $6,9 \%$ & $4,3 \%$ & $0,0 \%$ \\
2-3 kali dalam sebulan & $0,0 \%$ & $12,2 \%$ & $10,3 \%$ & $0,0 \%$ & $16,7 \%$ \\
1 kali sebulan & $0,0 \%$ & $13,3 \%$ & $6,9 \%$ & $8,7 \%$ & $0,0 \%$ \\
Setiap 2-3 bulan sekali & $35,3 \%$ & $35,7 \%$ & $41,4 \%$ & $52,2 \%$ & $33,3 \%$ \\
2 kali setahun & $35,3 \%$ & $23,5 \%$ & $10,3 \%$ & $26,1 \%$ & $16,7 \%$ \\
Setahun sekali & $23,5 \%$ & $11,4 \%$ & $20,7 \%$ & $8,7 \%$ & $33,3 \%$ \\
Tidak pernah & $5,9 \%$ & $1,2 \%$ & $0,0 \%$ & $0,0 \%$ & $0,0 \%$ \\
\hline
\end{tabular}

Sumber: Hasil pengolahan penulis (2021) 
Hasil penelitian diperoleh bahwa konsumen Indonesia hanya sebanyak 10,51\% yang sudah pernah melakukan pembelian produk UMKM sustainable fashion, sedangkan mayoritas $(89,5 \%)$ belum pernah membeli produk UMKM sustainable fashion, namun dari 89,5\% tersebut, 53,31\% sudah mulai mempertimbangkan untuk melakukan pembelian produk UMKM sustainable fashion. Lebih lanjut, dari hasil penelitian turut diperoleh bahwa sifat keberlanjutan (ramah lingkungan dan berperilaku etis terhadap pekerja) belum menjadi prioritas dalam pembelian produk pakaian. Pertimbangan utama konsumen dalam melakukan pembelian pakaian adalah harga dan kualitas, seperti yang terlihat dalam Gambar 2.

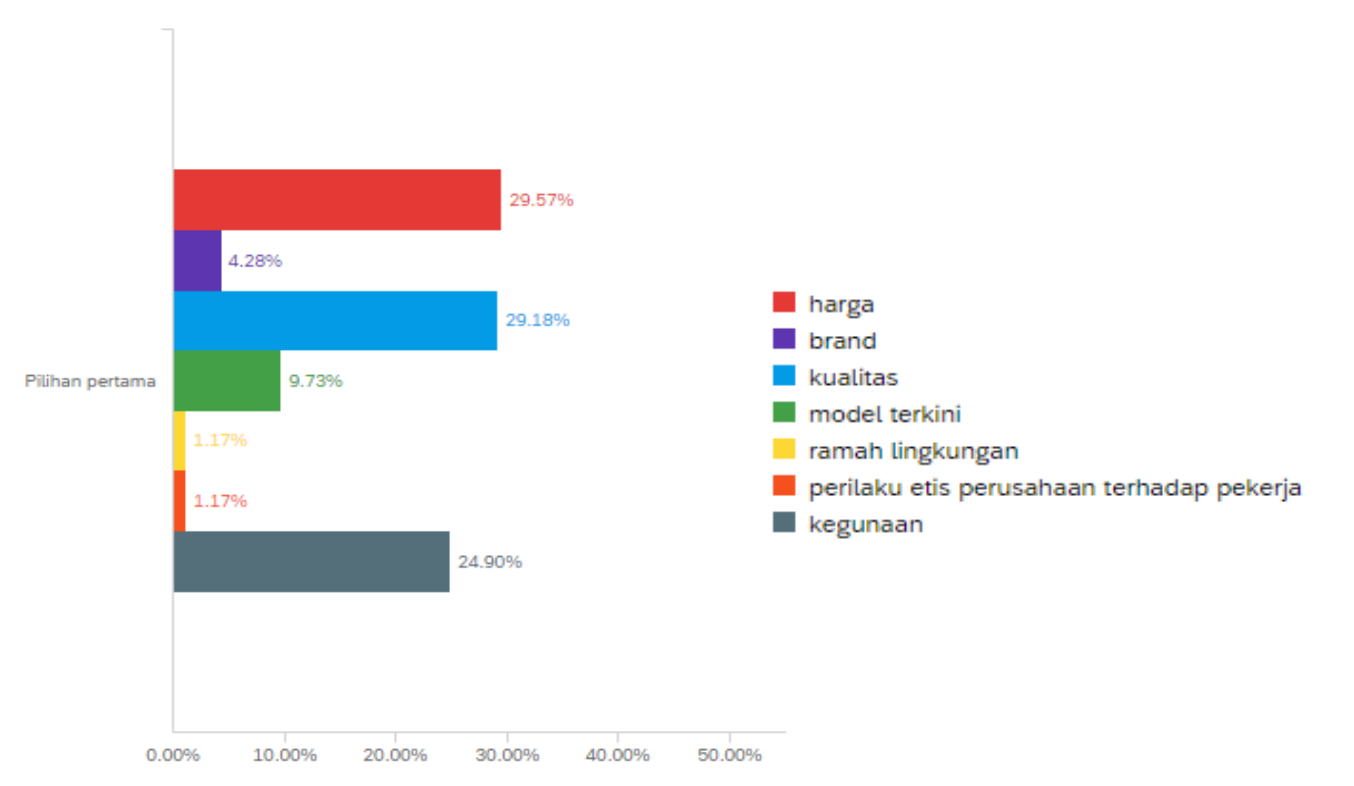

Gambar 2. Pertimbangan utama pembelian pakaian

Sumber: Hasil pengolahan penulis (2021)

Dari hasil analisis deskriptif masing-masing variabel, diperoleh rata-rata seperti yang terlihat dalam Tabel 2. Hasil rata-rata ini dimasukkan dalam rentang kriteria dan diperoleh bahwa pengetahuan konsumen akan sustainable fashion masih rendah. Sementara, kepercayaan terhadap perilaku bisnis UMKM sustainable fashion masuk dalam kategori tinggi. Purchase intention produk UMKM sustainable fashion, jika dilihat dari hasil analisis deskriptif, masuk ke dalam kategori sangat tinggi.

Tabel 2. Hasil analisis deskriptif

\begin{tabular}{lcl}
\hline \multicolumn{1}{c}{ Variabel } & N & Mean \\
\hline Pengetahuan & 257 & 15,82 \\
Kepercayaan & 257 & 18,2 \\
Purchase intention & 257 & 20,5 \\
\hline
\end{tabular}

Sumber: Hasil pengolahan penulis (2021)

\subsection{Hasil regresi}

Regresi merupakan langkah analisis yang diperlukan untuk melihat pengaruh knowledge terhadap purchase intention yang dimediasi oleh kepercayaan. Pengujian $\mathrm{H}_{1}$ dilakukan dengan analisis regresi yang dapat dilihat pada Tabel 3 .

Tabel 3. Hasil regresi pengaruh knowledge terhadap kepercayaan

\begin{tabular}{lcccccc}
\hline DV & $\mathrm{R}^{2}$ & ANOVA Sig. & IV & B & Beta & Sig. (t-test) \\
\hline Trust & $34 \%$ & $<0,001$ & Know & 0,650 & 0,583 & $<0,001$ \\
\hline
\end{tabular}

Sumber: Hasil pengolahan penulis (2021) 
Nilai R-square pada Tabel 3 menunjukkan bahwa hasil variasi variabel knowledge memengaruhi variabel kepercayaan sebesar 34\%. Model regresi memperlihatkan bahwa prediksi variabel knowledge terhadap kepercayaan menghasilkan koefisien sebesar $0,583(\beta=0,584, p<0,001)$ yang selanjutnya disebut jalur a. Berdasarkan Tabel 3, maka dapat mengonfirmasi hipotesis 1 yaitu bahwa terdapat pengaruh antara pengetahuan fashion yang berkelanjutan yang dimiliki konsumen terhadap kepercayaan (trust) konsumen.

Tabel 4. Hasil regresi pengaruh knowledge dan kepercayaan terhadap purchase intention

\begin{tabular}{ccccccc}
\hline DV & $\mathrm{R}^{2}$ & ANOVA Sig. & IV & B & Beta & Sig. (t-test) \\
\hline MB & $40,5 \%$ & $<0,001$ & know & 0,303 & 0,272 & $<0,001$ \\
& & & trust & 0,576 & 0,518 & $<0,001$ \\
\hline
\end{tabular}

Sumber: Hasil pengolahan penulis (2021)

Pengujian hipotesis 2 dan 3 dapat dilihat dari Tabel 4, di mana dari hasil regresi diperoleh nilai Rsquare sebesar $40,5 \%$ yang menunjukkan bahwa variasi variabel knowledge dan kepercayaan dapat menjelaskan variasi variabel purchase intention sebesar 40,5\%. Selanjutnya, model regresi menunjukkan bahwa prediksi knowledge terhadap purchase intention menghasilkan koefisien sebesar $0,272(\beta=0,272, p<0,001)$ yang selanjutnya disebut dengan jalur $\mathrm{c}$. Berdasarkan hasil tersebut, maka hipotesis 2 yang menyatakan terdapat pengaruh signifikan antara pengetahuan (knowledge) fashion berkelanjutan yang dimiliki konsumen terhadap purchase intention produk UMKM sustainable fashion terkonfirmasi.

Selanjutnya, hasil uji regresi menunjukkan bahwa kepercayaan dapat memprediksi purchase intention dengan menghasilkan koefisien 0,518 $(\beta=0,518, \mathrm{p}<0,001)$ di mana selanjutnya disebut dengan jalur b. Berdasarkan hasil regresi yang dapat dilihat pada Tabel 4, maka hipotesis 3 yang menyatakan bahwa terdapat pengaruh kepercayaan terhadap purchase intention terkonfirmasi. Rangkuman hasil koefisien dapat dilihat pada Gambar 3.

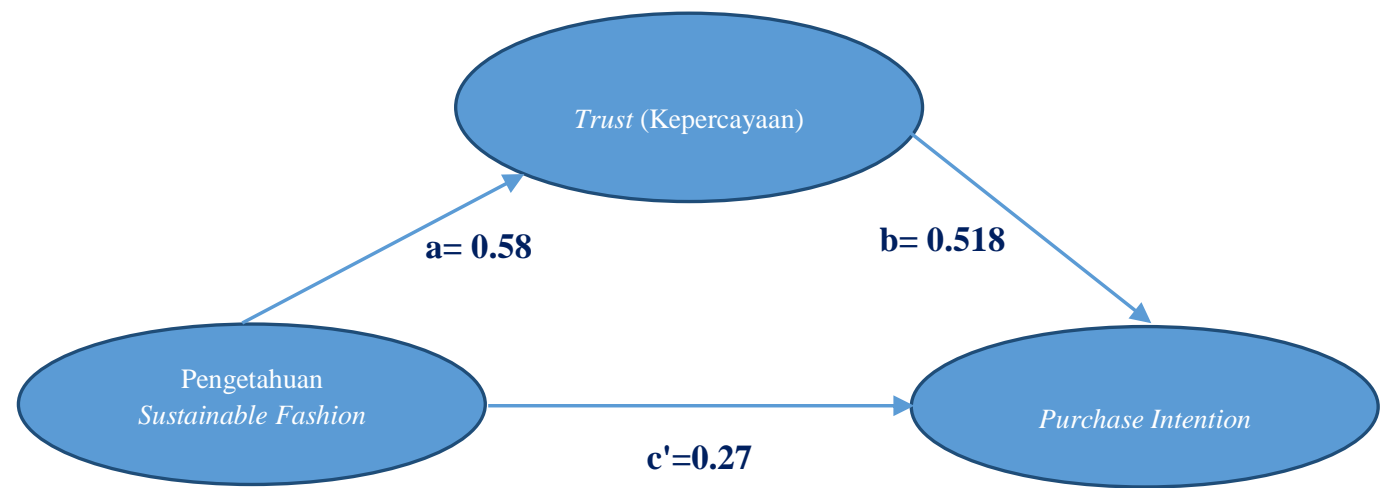

Gambar 3. Koefisien pengaruh kepercayaan-purchase intention dan pengetahuan

Sumber: Hasil pengolahan penulis (2021)

Langkah selanjutnya adalah untuk melihat ketepatan model mediasi dari rangkaian uji regresi yang telah dilakukan sebelumnya. Ketepatan model mediasi dapat dilakukan dengan cara melihat efek langsung dan efek tidak langsung knowledge terhadap purchase intention produk UMKM sustainable fashion yang dimediasi oleh kepercayaan. Uji mediasi dilakukan dengan dibantu dengan software JASP versi 0.14.1. Dari tabel uji mediasi terlihat bahwa knowledge memiliki direct effect yang signifikan terhadap purchase intention ( $\mathrm{p}<0,001)$ dengan nilai koefisien estimate yang lebih kecil dibandingkan dengan hasil regresi sebelumnya $(0,27)$ menjadi 0,095 , sedangkan jika melalui variabel kepercayaan sebagai mediator, pengetahuan ditemukan memiliki indirect effect yang signifikan ( $\mathrm{p}<0,001)$, artinya pengetahuan dapat berkontribusi dalam meningkatkan purchase intention dengan kepercayaan sebagai mediator parsial. Dengan demikian, dapat disimpulkan bahwa kepercayaan berperan untuk membantu menentukan purchase intention konsumen UMKM sustainable fashion. 
Tabel 5. Hasil model mediasi

\begin{tabular}{llcc}
\hline \multicolumn{1}{c}{ Efek } & \multicolumn{1}{c}{ Model } & Estimate & $\mathrm{P}$ \\
\hline Direct & Know $\rightarrow$ PI & 0,095 & $<0,001$ \\
Indirect & Know $\rightarrow$ Trust $\rightarrow$ PI & 0,0044 & $<0,001$ \\
Total & Know $\rightarrow$ PI & 0,139 & $<0,001$ \\
\hline
\end{tabular}

Sumber: Hasil pengolahan penulis (2021)

\subsection{Pembahasan}

Tujuan penelitian ini dilakukan adalah untuk mengonfirmasi bahwa pengetahuan konsumen mengenai sustainable fashion akan memengaruhi purchase intention produk UMKM sustainable fashion yang dimediasi oleh kepercayaan. Hasil penelitian menunjukkan bahwa persepsi knowledge konsumen terkait sustainable fashion akan menentukan purchase intention konsumen terhadap produk UMKM sustainable fashion. Hal ini sesuai dengan hasil penelitian yang dilakukan Hussain et al. (2014) yang menyatakan bahwa seseorang yang memiliki pengetahuan (knowledge) lingkungan akan memengaruhi preferensi individu tersebut dalam niat membeli produk yang hijau. Dari hasil penelitian diperoleh dalam analisis deskriptif bahwa persepsi knowledge responden rata-rata masih dalam kategori rendah, artinya konsumen belum memiliki pengetahuan kesadaran lingkungan, pengetahuan mengenai fashion yang berkelanjutan, gerakan hijau dalam bisnis fashion, UMKM yang menjual produk fashion, dan kegiatan produksi fast fashion yang saat ini merusak lingkungan. Sementara, pengetahuan akan komponenkomponen tersebut dapat memengaruhi purchase intention. Hal ini turut terlihat dari potensi konsumen yang berniat beli untuk produk UMKM sustainable fashion sebanyak 53,31\%. Namun, persepsi pengetahuan mengenai sustainable fashion ini terkonfirmasi dapat dibantu oleh adanya kepercayaan dari konsumen terhadap UMKM, sehingga pada akhirnya pengetahuan yang dimiliki konsumen ini dapat mendorong niat beli produk UMKM sustainable fashion. Hal ini turut mengonfirmasi penelitian yang dilakukan Wang et al. (2019).

Hasil penelitian menunjukkan bahwa responden memiliki kepercayaan terhadap UMKM sustainable fashion bahwa UMKM akan menjalankan bisnis yang terpercaya, sesuai harapan dan menjalankan bisnisnya sesuai dengan yang dijanjikan pada setiap produknya. Hasil deskriptif ini dapat diartikan bahwa UMKM sustainable fashion dipercaya menjadi pelaku bisnis yang berintegritas sehingga hal ini dapat menjadi kekuatan bagi UMKM untuk membangun komunikasi dalam mengedukasi pengetahuan konsumen akan praktik fashion yang berkelanjutan karena dengan adanya bantuan rasa percaya yang dimiliki konsumen tentunya akan mendorong niat beli produk UMKM sustainable fashion.

\section{SIMPULAN DAN SARAN}

Seluruh hipotesis dalam penelitian ini terjawab, sehingga hasil penelitian menjawab tujuan penelitian. Hasil penelitian ini mengonfirmasi temuan penelitian sebelumnya namun dengan obyek UMKM, di mana pada penelitian sebelumnya obyek penelitian adalah perusahaan fashion yang berskala besar. Obyek studi UMKM menjadi sesuatu yang perlu diteliti lebih dalam untuk ke depannya oleh akademisi karena hasil studi memiliki dampak praktis yang besar untuk mengembangkan UMKM, sehingga ke depannya perlu diteliti kesiapan UMKM menjadi oraganisasi yang berkelanjutan sebagai lanjutan untuk penelitian berikutnya. Simpulan yang dapat diambil adalah pengetahuan (knowledge) dapat memprediksi kepercayaan dan niat beli produk UMKM sustainable fashion. Kepercayaan konsumen turut menjadi prediktor dari niat produk UMKM sustainable fashion, sekaligus sebagai mediator parsial dalam hubungan antara pengetahuan dan niat beli produk UMKM sustainable fashion. Hasil penelitian ini membawa implikasi bahwa UMKM sustainable fashion hendaknya memfokuskan kegiatan promosinya untuk peningkatan pengetahuan konsumen terkait konteks fashion yang berkelanjutan, sehingga ketika pengetahuan konsumen meningkat maka akan mendorong kepercayaan konsumen terhadap produk UMKM sustainable fashion. Kepercayaan yang meningkat nantinya akan mendorong konsumen untuk memiliki niat beli dan berujung pada proses pembelian. Peran varians variabel independen dalam penelitian ini hanya menyumbang $40,5 \%$ dalam menjelaskan varians variabel niat beli, sehingga masih terdapat variabel penting lainnya yang belum diakomodir dalam penelitian ini, seperti willingness to pay yang menjadi kunci dalam mendorong perilaku keputusan pembelian produk 
hijau dan bauran pemasaran lainnya seperti harga, promosi, dan distribusi. Variabel-variabel tersebut dapat dikaji dalam penelitian selanjutnya. Selain itu, peran generasi dan peran jenis kelamin dapat dipertimbangkan untuk menjadi moderator pada penelitian selanjutnya agar dapat membantu proses segmentasi konsumen UMKM sustainable fashion.

\section{ACKNOWLEDGEMENTS}

Penulis mengucapkan terima kasih kepada:

1. Kementerian Riset dan Teknologi/ Badan Riset dan Inovasi Nasional (Kemenristek/ BRIN) tahun 2021 yang telah memberikan pendanaan pada program penelitian ini.

2. Unit Research Center and Case Clearing House Sekolah Tinggi Manajemen PPM, khususnya Research Center and Case Clearing House (RC-CCH) Dhinar Silalahi yang telah mendampingi proses penelitian.

3. Ribka Cantia Jans (SMB 15), mahasiswa Sekolah Tinggi Manajemen PPM yang membantu koordinasi pengumpulan data.

\section{REFERENSI}

Bank Indonesia. (2012). Kajian kesiapan UMKM. https://www.bi.go.id/id/publikasi/laporantahunan/bi/Pages/Laporan Tahunan Bank Indonesia Tahun 2012.aspx

Binet, F., Coste-Manière, I., Decombes, C., Grasselli, Y., Ouedermi, D., \& Ramchandani, M. (2018). Fast fashion and sustainable consumption. In Fast Fashion, Fashion Brands and Sustainable Consumption, 19-35. https://doi.org/https://doi.org/10.1007/978-981-13-1268-7_2

Bonn, M. A., Cronin, J. J., \& Cho, M. (2016). Do environmental sustainable practices of organic wine suppliers affect consumers' behavioral intentions? The moderating role of trust. Cornell Hospitality Quarterly, 57(1), 21-37. https://doi.org/10.1177/1938965515576567

Carey, L., \& Cervellon, M. C. (2014). Ethical fashion dimensions: Pictorial and auditory depictions through three cultural perspectives. Journal of Fashion Marketing and Management, 18(4), 483506. https://doi.org/10.1108/JFMM-11-2012-0067

Chen, Y. S., \& Chang, C. H. (2012). Enhance green purchase intentions: The roles of green perceived value, green perceived risk, and green trust. Management Decision, 50(3), 502-520. https://doi.org/10.1108/00251741211216250

Claudio, L. (2007). Waste couture: Environmental impact of the clothing industry. Environmental Health Perspectives, 115(9), 449-454. https://doi.org/10.1289/ehp.115-a449

Direktorat Riset dan Pengembangan Ekonomi Kreatif Deputi Riset Edukasi dan Pengembangan Badan Ekonomi Kreatif. (2017). Data statistik dan hasil survei ekonomi kreatif (Kerjasama Badan Ekonomi Kreatif dan Badan Pusat Statistik). https://psmk.kemdikbud.go.id/

García-Torres, S., Rey-Garcia, M., \& Albareda-Vivo, L. (2017). Effective disclosure in the fast-fashion industry: From sustainability reporting to action. Sustainability (Switzerland), 9(12), 1-27. https://doi.org/10.3390/su9122256

Han, J., Seo, Y., \& Ko, E. (2017). Staging luxury experiences for understanding sustainable fashion consumption: A balance theory application. Journal of Business Research, 74(May), 162-167. https://doi.org/10.1016/j.jbusres.2016.10.029

Hussain, M. A., Khokhar, M. F., \& Asad, A. (2014). Green knowledge effects on consumers' purchasing decision: A case study of Pakistan. Global Journal of Management and Business Research, 14(6), 9-15. https://journalofbusiness.org/index.php/GJMBR/article/view/1555/1458

Kostadinova, E. (2016). Sustainable consumer behavior: Literature overview. Economic Alternative, University of National and World Economy, 2(June), 224-234. https://www.unwe.bg/uploads/Alternatives/Elena_9_ALTERNATIVI_br2_2016-en.pdf

Krejcie, R. V., \& Morgan, D. W. (1970). Determining sample size for research activities. Educational $\begin{array}{lll}\text { and Psychological 30(3), } & \text { 607-610. }\end{array}$ https://home.kku.ac.th/sompong/guest_speaker/KrejcieandMorgan_article.pdf

Liu, Y., Liu, M. T., Pérez, A., Chan, W., Collado, J., \& Mo, Z. (2021). The importance of knowledge and trust for ethical fashion consumption. Asia Pacific Journal of Marketing and Logistics, 33(5), 1175-1194. https://doi.org/10.1108/APJML-02-2020-0081 
Martinayanti, N. M. P., \& Setiawan, P. Y. (2016). Peran kepercayaan dalam memediasi persepsi risiko pada niat beli produk fashion via Instagram di Kota Denpasar. E-Jurnal Manajemen Universitas Udayana, 5(4). 2026-2053. https://ojs.unud.ac.id/index.php/Manajemen/article/view/17814

Mei, O. J., Ling, K. C., \& Piew, T. H. (2012). The antecedents of green purchase intention among Malaysian consumers. Asian Social Science, 8(13), 248-263. https://doi.org/10.5539/ass.v8n13p248

Meulenberg, M. T. G. (2003). Consument en burger, betekenis voor de markt van landbouwproducten en voedingsmiddelen. Tijdschrift Voor Sociaalwetenschappelijk Onderzoek van de Landbouw, $18(1)$, http://www.narcis.nl/publication/RecordID/oai\%3Alibrary.wur.nl\%3Awurpubs\%2F321060

Neumann, H. L., Martinez, L. M., \& Martinez, L. F. (2020). Sustainability efforts in the fast fashion industry: Consumer perception, trust, and purchase intention. Sustainability Accounting, Management and Policy Journal, 12(3), 571-590. https://doi.org/10.1108/SAMPJ-11-2019-0405

Putra, I. I. (2020, Maret 23). Statistik ketenagakerjaan DKI Jakarta 2019. Portal Statistik Sektoral Provinsi DKI Jakarta. http://statistik.jakarta.go.id/statistik-ketenagakerjaan-dki-jakarta-2019

Quoquab, F., Mohammad, J., \& Sukari, N. N. (2019). A multiple-item scale for measuring "sustainable consumption behaviour" construct: Development and psychometric evaluation. Asia Pacific Journal of Marketing and Logistics, 31(4), 791-816. https://doi.org/10.1108/APJML-02-20180047

Reisch, L., Eberle, U., \& Lorek, S. (2013). Sustainable food consumption: An overview of contemporary issues and policies. Sustainability: Science, Practice, and Policy, 9(2), 7-25. https://doi.org/10.1080/15487733.2013.11908111

Rosadi, D. (2021). Survei KIC: Baru 28 persen konsumen memahami produk hijau. katadata.co.id https://katadata.co.id/doddyrosadi/ekonomi-hijau/61725e378f331/survei-kic-baru-28-persenkonsumen-memahami-produk-hijau

Shen, D., Richards, J., \& Liu, F. (2013). Consumers' knowledge of sustainable fashion. Proceedings of the Marketing Management Association, 23(2), 134-147. http://www.mmaglobal.org/publications/MMJ/MMJ-Issues/2013-Fall/MMJ-2013-Fall-Vol23Issue2-Shen-Richards-Liu-pp134-147.pdf

Suk, H. (2015). Consumers' perception of fashion companies' sustainability and its effect on trust, preference, and purchase intention. Journal of the Korean Society of Clothing and Textiles, 39(5), 656-671. https://doi.org/10.5850/jksct.2015.39.5.656

Susilo, D. (2014). Analisis program corporate social marketing, pengetahuan konsumen dan reputasi perusahaaan dalam menciptakan green consumerism (Program tumbler Starbuck on the go). Jurnal Manajemen Pemasaran, 8(1), 9-17. https://doi.org/10.9744/pemasaran.8.1.9-17

Wang, H., Ma, B., \& Bai, R. (2019). How does green product knowledge effectively promote green $\begin{array}{llll}\text { purchase intention?. } & \text { Sustainability } & 11(4), & 13 .\end{array}$ https://doi.org/https://doi.org/10.3390/su11041193 